\title{
BMJ open Predictors of early death in female patients with breast cancer in the UK: a cohort study
}

\author{
Ceilidh Stapelkamp, ${ }^{1}$ Lars Holmberg, ${ }^{2}$ Daniela Tataru, $^{3}$ Henrik Møller, ${ }^{3}$ \\ David Robinson ${ }^{3}$
}

To cite: Stapelkamp C, Holmberg L, Tataru D, et al. Predictors of early death in female patients with breast cancer in the UK: a cohort study. BMJ Open 2011;1: e000247. doi:10.1136/ bmjopen-2011-000247

- Prepublication history for this paper is available online. To view these files please visit the journal online (http:// bmjopen.bmj.com).

Received 1 July 2011 Accepted 30 August 2011

This final article is available for use under the terms of the Creative Commons Attribution Non-Commercial 2.0 Licence; see http://bmjopen.bmj.com

1Bazian Ltd, 10 Fitzroy Square, London, UK ${ }^{2}$ Division of Cancer Studies, Cancer Epidemiology Group Guy's Hospital, London, UK ${ }^{3}$ Thames Cancer Registry, King's College London, London, UK

Correspondence to Professor Lars Holmberg; lars.holmberg@kcl.ac.uk

\section{ABSTRACT}

Objective: To identify factors predicting early death in women with breast cancer.

Design: Cohort study.

Setting: 29 trusts across seven cancer networks in the North Thames area.

Participants: 15037 women with primary breast cancer diagnosed between January 1996 and December 2005.

Methods: Logistic regression analyses to determine predictors of early death and factors associated with lack of surgical treatment.

Main exposures: Age at diagnosis, mode of presentation, ethnicity, disease severity, comorbidities, treatment and period of diagnosis in relation to the Cancer Plan (the NHS's strategy in 2000 for investment in and reform of cancer services).

Main outcome measures: Death from any cause within 1 year of diagnosis, and receipt of surgical treatment.

Results: By 31 December 2006, 4765 women had died, 980 in the year after diagnosis. Older age and disease severity independently predicted early death. Women over 80 were more likely to die early than women under 50 (OR 8.05, 95\% Cl 5.96 to 10.88). Presence of distant metastases on diagnosis increased the odds of early death more than eightfold (OR 8.41, $95 \% \mathrm{Cl} 6.49$ to 10.89). Two or more recorded comorbidities were associated with a nearly fourfold increase. There was a significant decrease in odds associated with surgery (OR $0.29,95 \% \mathrm{Cl} 0.24$ to 0.35 ). Independently of disease severity and comorbidities, women over 70 were less likely than those under 50 to be treated surgically and this was even more pronounced in those aged over 80 (OR $0.09,95 \% \mathrm{Cl} 0.07$ to 0.10$)$. Other factors independently associated with a reduced likelihood of surgery included a non-screening presentation, nonwhite ethnicity and additional comorbidities.

Conclusions: These findings may partially explain the survival discrepancies between the UK and other European countries in female patients with breast cancer. The study identifies a group of women with a particularly poor prognosis for whom interventions aiming at early detection may be targeted.

\section{ARTICLE SUMMARY}

\section{Article focus}

- Several studies have shown that the UK has lower survival for breast cancer than some other European countries with a similar expenditure on healthcare.

- Differences have been shown to occur mainly in older patients and in the first year after diagnosis.

- Several reasons/explanations have been proposed.

Key messages

- This study shows that patients with breast cancer dying in the first year after diagnosis are more likely to be older and have more advanced disease and existing comorbidities.

- Surgical treatment and (to a lesser extent) radiotherapy and tamoxifen usage were associated with a reduced risk of early death.

- The likelihood of receiving surgery was inversely related to age, independently of comorbidity and disease severity.

- These findings suggest that early detection, management of comorbidities and optimisation of treatment of older patients are important target areas to improve outcomes.

Strengths and limitations of this study

- This is a large cohort of women with a diagnosis of breast cancer, and the results may be generalisable to women treated for breast cancer in the UK during the same time period.

- Many variables that may be related to both risk factors and outcomes have not been assessed in this study. However, their correlation with death within a year would have to be very strong to explain the strong associations seen in our data.

\section{INTRODUCTION}

Despite the decline in breast cancer mortality seen in the UK since the late 1980s, survival rates are still substantially lower than in many other European countries. ${ }^{1}{ }^{2}$ It has been difficult to pinpoint the reasons for these differences. One important observation in some studies remains unexplained, namely 
that of poorer survival in UK patients soon after their diagnosis. Sant $e t a l^{3}$ demonstrated a higher risk of death in women with breast cancer in the UK in the first 6 months after diagnosis than in other European countries. This was particularly pronounced for the youngest (under 29 years) and oldest (over 80 years) age groups. Six months from diagnosis, survival patterns in the UK became more similar to those in the other European countries. Further analysis of the survival differential has revealed that disparities between the UK and northern European countries (Sweden and Norway) occur mainly for older women in the first year after diagnosis. ${ }^{4}$ Eightyone per cent of the excess UK deaths occur within 2 years of diagnosis.

Beral and Peto ${ }^{5}$ have suggested that observed differences in survival may be due to bias relating to artefacts in cancer registration rather than to genuine differences in diagnosis and management of breast cancer. However, a recent study by Møller $e t a t^{6}$ has shown that such effects are unlikely to make a significant contribution to observed differences in survival. The effects of incomplete ascertainment and registration from death certificates only on survival comparisons based on cancer registry data have been investigated in detail by Robinson et $^{a l^{7}}{ }^{7}$

The aim of this study was to investigate factors associated with early mortality (within 1 year after diagnosis) in a sample of UK women given a diagnosis of breast cancer during 1996-2005. Since surgical intervention with a curative intent is strongly related to reduced mortality, a secondary aim of the study was to identify the patient characteristics most often associated with the failure to use this treatment option.

\section{SUBJECTS AND METHODS}

We conducted a cohort study using data from the North Thames Prospective Audit of Breast Cancer, set up in 1996 by Health Authorities in the North Thames area to monitor the implementation of the Calman-Hine recommendations in 29 trusts in seven participating cancer networks: North London, North East London, West London, South West London (Royal Marsden Hospital, Brompton Road), Mount Vernon, Mid-Anglia and South Essex. The audit used a common dataset and a standard proforma across the providers to collect detailed demographic, diagnostic and treatment data for all new primary cases of malignant female breast cancer diagnosed between January 1996 and December 2005. Trained data collectors used either Thames Cancer Registry (TCR) Access-based software or the British Association of Surgical Oncology software for breast audit to record information. The number of participating trusts varied from year to year, with a maximum of 26 trusts submitting partial or complete datasets in 2000 and a minimum of seven trusts submitting data in 2005.

Women were followed from their date of entry into the audit to death or censoring at 31 December 2006, an average of 5.6 years. Date of death was confirmed through linking patients to the NHS Central Register using the NHS Strategic Tracing Service or matching with records in the TCR. For those who were neither traced nor matched, date of death was taken from the breast audit database, if it was recorded. Women who were either traced or matched but who had no date of death in any of the three databases were assumed to be alive at 31 December 2006. Women who could not be traced in the NHS Central Register or matched to the TCR database and who had no date of death recorded in the audit database were excluded from analyses, as we could not be sure of their vital status. The study also excluded women with in situ breast cancer without any invasive component at diagnosis. After these exclusions, a total of 15037 women were available for analysis.

Data on different treatment modes (surgery, radiotherapy, chemotherapy and tamoxifen) were taken from the audit database, augmented by information from the TCR database where possible. Cases were matched to Hospital Episode Statistics (HES) data using name, NHS number, date of birth and date of diagnosis within 90 days of that recorded in the audit database in order to obtain further information on receipt of surgery. Women with a C50 diagnosis (breast cancer) and a B or T8 code in the HES surgery field were regarded as having had surgery. Only 98 cases were recoded on this basis, illustrating the completeness of the audit database in this respect.

Cause of death was available from the TCR database for $85 \%$ of the women who died during the study period. A categorical variable accounting for the calendar period of diagnosis was included to adjust for diagnosis and treatment in relation to the implementation of the Cancer Plan (the NHS's strategy in 2000 for investment in and reform of cancer services). As per the methodology of Rachet et $a l,{ }^{8}$ the following periods were considered: before 27 September 2000 (when the plan was published); 28 September 2000 to 31 December 2003 (initialisation period); after 01 January 2004 (implementation). Patient age was categorised as: $<50$ years, 50-59 years, 60-69 years, $70-79$ years and 80 years and over. Pathological tumour size was assigned to one of five groups: $<10 \mathrm{~mm}, 10-19 \mathrm{~mm}, 20-39 \mathrm{~mm}$, $40-49 \mathrm{~mm}$ and $50 \mathrm{~mm}$ and over. Information on additional diagnoses was obtained from the matched HES dataset and was used to determine the Charlson Comorbidity Index for matched patients. This is a weighted index based on the number and severity of 17 potential serious comorbid conditions that affect mortality. ${ }^{9}$ The index was categorised into the groups 0 , 1 and $2+$.

Clinical, demographic, pathological and treatmentrelated factors were compared between women who died from any cause within 1 year of their diagnosis and those who survived beyond this year. All-cause mortality, rather than death from breast cancer, was used partly because 
specific cause of death was not known in $15 \%$ of the women, but also because the international study ${ }^{4}$ that highlighted the adverse survival in English women in the first year after diagnosis was also based on all-cause mortality. An analysis restricted to breast cancer-specific mortality produced broadly similar results.

Univariate analyses were performed using $\chi^{2}$ tests and unadjusted (bivariate) logistic regression models. A multivariate logistic regression model investigated the independent contribution of all covariates. This model included surgery but not collinear covariates - that is, variables that were only known for patients who had surgery, namely tumour size and node status.

The regression models assessed the effects of age, ethnicity, mode of presentation (screening, symptoms or incidental), distant metastases at diagnosis, comorbidities, period of diagnosis and treatments (surgery, radiotherapy, tamoxifen and chemotherapy) on early death from any cause. The results are presented as ORs, both unadjusted (univariate) and fully adjusted (multivariate), with $95 \%$ CIs.

Additional logistic regression models were used to determine which factors were associated with use of surgery. All analyses were conducted using Stata V.10.

\section{RESULTS}

The study population consisted of 15037 women, of whom $4456(30 \%)$ were over 70 years old at the time of their diagnosis. The majority of women $(78 \%)$ presented symptomatically, and $82 \%$ of those with known ethnicity were recorded as white. Over a mean follow-up of 5.6 years, there were 4765 deaths. Table 1 shows the underlying cause of death in these women. A total of 980 women $(6.5 \%$ of the total cohort and $20.6 \%$ of all deaths) died within a year of their diagnosis, and, of these, 464 women were known to have died from breast cancer. Among those for whom the cause of death was known, there was no significant difference in the proportions dying from different causes between those who died within or after the first year since diagnosis $\left(\chi^{2}=10.6 ; 9 \mathrm{df} ; \mathrm{p}=0.30\right)$. However, significantly more of the women who died early had an unrecorded cause of death $(26 \%$ vs $12 \%)$.

Table 2 describes the characteristics of women who survived 1 year beyond diagnosis and those who did not, and table 3 shows the results of the logistic regression analyses. In univariate analyses ( $\chi^{2}$ values in table 2 and unadjusted ORs in table 3 ), older age ( $>60$ years), white ethnicity, distant metastases at diagnosis, positive nodes and larger tumours $(>20 \mathrm{~mm})$ were all significantly linked with death within 1 year of diagnosis $(p<0.001$ for all $\chi^{2}$ tests). Comorbidities on diagnosis were also associated with an increased likelihood of early death (Charlson Index $\geq 2$ : OR 5.55, 95\% CI 4.56 to 6.76). Women presenting because of symptoms (OR 7.91, 95\% CI 5.21 to 12.01) or whose cancer was discovered incidentally (OR 11.98 , 95\% CI 7.37 to 19.48) were significantly more likely to die early, compared with those whose cancer was identified through screening. 'Incidental' cancers comprised non-symptomatic referrals from any source other than routine screening or the patient's general practitioner.

Surgical treatment was associated with highly significantly reduced odds of early death from any cause (OR $0.12,95 \%$ CI 0.11 to 0.14 ), as was treatment with chemotherapy (OR $0.60,95 \%$ CI 0.51 to 0.71 ) and radiotherapy (OR $0.27,95 \%$ CI 0.23 to 0.32 ). There was no significant association between tamoxifen usage and early death (OR $0.94,95 \%$ CI 0.79 to 1.12 ). The time period in which women were diagnosed (before, during or after implementation of the Cancer Plan) was not significantly associated with death within a year of diagnosis in univariate models $\left(\chi^{2}=3.54 ; \mathrm{p}=0.17\right)$.

The results of the multivariate logistic regression analysis to assess the factors independently associated with early death are shown as the adjusted ORs in table 3. This model excluded tumour size and nodal status, which are only known in women who received

Table 1 Cause of death in women with breast cancer by length of survival

\begin{tabular}{|c|c|c|c|}
\hline \multirow[b]{2}{*}{ Cause of death } & \multicolumn{2}{|l|}{ Survival } & \multirow[b]{2}{*}{$\begin{array}{l}\text { Total } \\
\text { Number (\%) }\end{array}$} \\
\hline & $\begin{array}{l}<1 \text { year from diagnosis } \\
\text { Number (\%) }\end{array}$ & $\begin{array}{l}>1 \text { year from diagnosis } \\
\text { Number }(\%)\end{array}$ & \\
\hline Breast cancer & 464 (63.9) & $2015(60.5)$ & $2479(61.1)$ \\
\hline Lung cancer & $4(0.6)$ & $38(1.1)$ & $42(1.0)$ \\
\hline Colorectal cancer & $3(0.4)$ & $32(1.0)$ & $35(0.9)$ \\
\hline Other/unspecified cancer & $39(5.4)$ & $232(7.0)$ & $271(6.7)$ \\
\hline Ischaemic heart disease & $34(4.7)$ & $137(4.1)$ & $171(4.2)$ \\
\hline Stroke & $14(1.9)$ & $79(2.4)$ & 93 (2.3) \\
\hline Other cardiovascular disease & $43(5.9)$ & $204(6.1)$ & $247(6.1)$ \\
\hline Senility & $16(2.2)$ & $92(2.8)$ & $108(2.7)$ \\
\hline Pneumonia & $38(5.2)$ & $205(6.2)$ & $243(6.0)$ \\
\hline All other causes & $71(9.8)$ & $294(8.8)$ & $365(9.0)$ \\
\hline Total with known cause of death & $726(100.0)$ & $3328(100.0)$ & $4054(100.0)$ \\
\hline Cause of death not known & $254(25.9)$ & $457(12.1)$ & $711(14.9)$ \\
\hline Total cases & 980 & 3785 & 4765 \\
\hline
\end{tabular}


Table 2 Characteristics of participants who did or did not survive the first year after diagnosis

\begin{tabular}{|c|c|c|c|}
\hline \multirow[b]{2}{*}{ Patient characteristic } & \multicolumn{2}{|l|}{ Survival } & \multirow[b]{2}{*}{ p Value } \\
\hline & $\begin{array}{l}<1 \text { year from diagnosis } \\
\text { Number }(\%)\end{array}$ & $\begin{array}{l}>1 \text { year from diagnosis } \\
\text { Number }(\%)\end{array}$ & \\
\hline \multicolumn{4}{|l|}{ Age at diagnosis (years) } \\
\hline$<50$ & $88(9.0)$ & $3712(26.4)$ & \multirow[t]{5}{*}{$<0.001$} \\
\hline $50-59$ & $91(9.3)$ & $3648(26.0)$ & \\
\hline $60-69$ & $148(15.1)$ & $2894(20.6)$ & \\
\hline $70-79$ & $270(27.6)$ & $2373(16.9)$ & \\
\hline$\geq 80$ & $383(39.1)$ & $1430(10.2)$ & \\
\hline \multicolumn{4}{|l|}{ Ethnicity } \\
\hline Non-white & $75(7.7)$ & $1983(14.1)$ & \multirow[t]{3}{*}{$<0.001$} \\
\hline White & $488(49.8)$ & 8610 (61.3) & \\
\hline Not known & $417(42.6)$ & $3464(24.6)$ & \\
\hline \multicolumn{4}{|c|}{ Distant metastases at diagnosis } \\
\hline No & $312(31.8)$ & 7977 (56.7) & \multirow[t]{3}{*}{$<0.001$} \\
\hline Yes & $156(15.9)$ & $271(1.9)$ & \\
\hline Not known & $512(52.2)$ & 5809 (41.3) & \\
\hline \multicolumn{4}{|l|}{ Tumour size (mm) } \\
\hline$<10$ & $12(1.2)$ & $1220(8.7)$ & \multirow[t]{6}{*}{$<0.001$} \\
\hline $10-19$ & $73(7.4)$ & $4016(28.6)$ & \\
\hline $20-39$ & $83(8.5)$ & $3103(22.1)$ & \\
\hline $40-49$ & $86(8.8)$ & 1953 (13.9) & \\
\hline$\geq 50$ & $99(10.1)$ & $799(5.7)$ & \\
\hline Not known & $627(64.0)$ & $2966(21.1)$ & \\
\hline \multicolumn{4}{|l|}{ Node status } \\
\hline Negative & $95(9.7)$ & $5492(39.1)$ & \multirow[t]{3}{*}{$<0.001$} \\
\hline Positive & $167(17.0)$ & $4213(30.0)$ & \\
\hline Not known & 718 (73.3) & $4352(31.0)$ & \\
\hline \multicolumn{4}{|c|}{ Charlson Index (comorbidities) } \\
\hline 0 (minor) & $203(20.7)$ & $6755(48.1)$ & \multirow[t]{4}{*}{$<0.001$} \\
\hline 1 (moderate) & $48(4.9)$ & $359(2.6)$ & \\
\hline$\geq 2$ (severe) & $231(23.6)$ & $1384(9.8)$ & \\
\hline Not known & $498(50.8)$ & $5559(39.5)$ & \\
\hline \multicolumn{4}{|c|}{ Diagnosis date (in relation to Cancer Plan) } \\
\hline Pre 2000 & $624(63.7)$ & $9057(64.4)$ & \multirow[t]{3}{*}{0.79} \\
\hline $2000-2003$ & $292(29.8)$ & $3897(27.7)$ & \\
\hline Post 2003 & $64(6.5)$ & $1103(7.8)$ & \\
\hline \multicolumn{4}{|l|}{ Presentation } \\
\hline Screening & $23(2.3)$ & 2274 (16.2) & \multirow[t]{4}{*}{$<0.001$} \\
\hline Symptoms & 763 (77.9) & $9531(67.8)$ & \\
\hline Incidental & $64(6.5)$ & $528(3.8)$ & \\
\hline Not known & 130 (13.3) & 1724 (12.3) & \\
\hline Surgery & & & \\
\hline No & 489 (49.9) & 1513 (10.8) & $<0.001$ \\
\hline Yes & 491 (50.1) & 12544 (89.2) & \\
\hline Radiotherapy & & & \\
\hline No & 454 (46.3) & 3395 (24.2) & $<0.001$ \\
\hline Yes & $256(26.1)$ & 7079 (50.4) & \\
\hline Not known & $270(27.6)$ & $3583(25.5)$ & \\
\hline Chemotherapy & & & \\
\hline No & $520(53.1)$ & $6482(46.1)$ & $<0.001$ \\
\hline Yes & $203(20.7)$ & 4200 (29.9) & \\
\hline Not known & 257 (26.2) & 3375 (24.0) & \\
\hline Tamoxifen & & & \\
\hline No & $172(17.6)$ & $2321(16.5)$ & 0.49 \\
\hline Yes & 601 (61.3) & 8630 (61.4) & \\
\hline Not known & $207(21.1)$ & 3106 (22.1) & \\
\hline Total cases & 980 & 14057 & \\
\hline
\end{tabular}


Table 3 Crude and adjusted ORs and 95\% Cls for early death from any cause

\begin{tabular}{|c|c|c|c|c|}
\hline \multirow[b]{2}{*}{ Factor } & \multirow[b]{2}{*}{ Number of cases } & \multirow{2}{*}{$\begin{array}{l}\text { Early deaths, } \\
\text { number }(\%)\end{array}$} & \multicolumn{2}{|l|}{ OR $(95 \% \mathrm{CI})$} \\
\hline & & & Unadjusted & Adjusted* \\
\hline \multicolumn{5}{|c|}{ Age at diagnosis (years) } \\
\hline$<50$ & 3800 & $88(2.3)$ & $1.00(-)$ & $1.00(-)$ \\
\hline $50-59$ & 3739 & $91(2.4)$ & $1.05(0.78$ to 1.42$)$ & 1.41 (1.03 to 1.93$)$ \\
\hline $60-69$ & 3042 & $148(4.9)$ & 2.16 (1.65 to 2.82$)$ & 2.61 (1.94 to 3.50$)$ \\
\hline $70-79$ & 2643 & $270(10.2)$ & 4.80 (3.75 to 6.14$)$ & 4.62 (3.45 to 6.18$)$ \\
\hline$\geq 80$ & 1813 & $383(21.1)$ & 11.30 (8.89 to 14.36$)$ & 8.05 (5.96 to 10.88$)$ \\
\hline \multicolumn{5}{|l|}{ Ethnicity } \\
\hline Non-white & 2058 & $75(3.6)$ & $1.00(-)$ & $1.00(-)$ \\
\hline White & 9098 & $488(5.4)$ & 1.50 (1.17 to 1.92$)$ & $1.25(0.96$ to 1.63$)$ \\
\hline Not known & 3881 & 417 (10.7) & 3.18 (2.47 to 4.09$)$ & 2.241 .70 to 2.94$)$ \\
\hline \multicolumn{5}{|c|}{ Distant metastases at diagnosis } \\
\hline No & 8289 & $312(3.8)$ & $1.00(-)$ & $1.00(-)$ \\
\hline Yes & 427 & $156(36.5)$ & $14.72(11.73$ to 18.47$)$ & 8.41 (6.49 to 10.89$)$ \\
\hline Not known & 6321 & $512(8.1)$ & 2.25 (1.95 to 2.60$)$ & 1.35 (1.13 to 1.60$)$ \\
\hline \multicolumn{5}{|c|}{ Tumour size (mm) } \\
\hline$<10$ & 1232 & $12(1.0)$ & $1.00(-)$ & - \\
\hline $10-19$ & 4089 & 73 (1.8) & 1.85 (1.00 to 3.41$)$ & - \\
\hline $20-39$ & 3186 & $83(2.6)$ & 2.72 (1.48 to 5.00$)$ & - \\
\hline $40-49$ & 2039 & $86(4.2)$ & 4.48 (2.44 to 8.22$)$ & - \\
\hline$\geq 50$ & 898 & 99 (11.0) & 12.60 (6.87 to 23.08$)$ & - \\
\hline Not known & 3593 & $627(17.4)$ & 21.4912 .09 to 38.20 ) & - \\
\hline \multicolumn{5}{|l|}{ Node status } \\
\hline Negative & 5587 & $95(1.7)$ & $1.00(-)$ & - \\
\hline Positive & 4380 & $167(3.8)$ & 2.29 (1.78 to 2.96$)$ & - \\
\hline Not known & 5070 & $718(14.2)$ & 9.54 (7.67 to 11.86$)$ & - \\
\hline \multicolumn{5}{|c|}{ Charlson Index (comorbidities) } \\
\hline 0 (minor) & 6958 & $203(2.9)$ & $1.00(-)$ & $1.00(-)$ \\
\hline 1 (moderate) & 407 & $48(11.8)$ & 4.45 (3.19 to 6.20$)$ & 2.54 (1.77 to 3.65$)$ \\
\hline $2+($ severe $)$ & 1615 & $231(14.3)$ & 5.55 (4.56 to 6.76$)$ & 3.55 (2.85 to 4.42$)$ \\
\hline Not known & 6057 & $498(8.2)$ & 2.98 (2.52 to 3.52$)$ & $1.10(0.90$ to 1.34$)$ \\
\hline \multicolumn{5}{|c|}{ Diagnosis date (in relation to Cancer Plan) } \\
\hline Pre 2000 & 9681 & $624(6.4)$ & $1.00(-)$ & $1.00(-)$ \\
\hline $2000-2003$ & 4189 & $292(7.0)$ & 1.09 (0.94 to 1.26$)$ & $0.90(0.75$ to 1.07 \\
\hline Post 2003 & 1167 & $64(5.5)$ & $0.84(0.65$ to 1.10$)$ & $0.71(0.52$ to 0.98$)$ \\
\hline \multicolumn{5}{|l|}{ Presentation } \\
\hline Screening & 2297 & $23(1.0)$ & $1.00(-)$ & $1.00(-)$ \\
\hline Symptoms & 10294 & $763(7.4)$ & $7.91(5.21$ to 12.01$)$ & $3.31(2.13$ to 5.14$)$ \\
\hline Incidental & 592 & $64(10.8)$ & 11.98 (7.37 to 19.48$)$ & 3.92 (2.30 to 6.66$)$ \\
\hline Not known & 1854 & $130(7.0)$ & 7.46 (4.76 to 11.67$)$ & 2.77 (1.72 to 4.48$)$ \\
\hline \multicolumn{5}{|l|}{ Surgery } \\
\hline No & 2002 & $489(24.4)$ & $1.00(-)$ & $1.00(-)$ \\
\hline Yes & 13035 & $491(3.8)$ & $0.12(0.11$ to 0.14$)$ & $0.29(0.24$ to 0.35$)$ \\
\hline \multicolumn{5}{|l|}{ Radiotherapy } \\
\hline No & 3849 & $454(11.8)$ & $1.00(-)$ & $1.00(-)$ \\
\hline Yes & 7335 & $256(3.5)$ & $0.27(0.23$ to 0.32$)$ & $0.61(0.51$ to 0.74$)$ \\
\hline Not known & 3853 & $270(7.0)$ & $0.56(0.48$ to 0.66$)$ & 0.65 (0.48 to 0.87$)$ \\
\hline \multicolumn{5}{|l|}{ Chemotherapy } \\
\hline No & 7002 & $520(7.4)$ & $1.00(-)$ & $1.00(-)$ \\
\hline Yes & 4403 & $203(4.6)$ & $0.60(0.51$ to 0.71$)$ & 1.49 (1.19 to 1.86$)$ \\
\hline Not known & 3632 & $257(7.1)$ & $0.95(0.81$ to 1.11$)$ & 1.20 (0.89 to 1.62$)$ \\
\hline \multicolumn{5}{|l|}{ Tamoxifen } \\
\hline No & 2493 & $172(6.9)$ & $1.00(-)$ & $1.00(-)$ \\
\hline Yes & 9231 & $601(6.5)$ & $0.94(0.79$ to 1.12$)$ & $0.64(0.51$ to 0.80$)$ \\
\hline Not known & 3313 & 207 (6.2) & $0.90(0.73$ to 1.11$)$ & $0.93(0.70$ to 1.24$)$ \\
\hline
\end{tabular}


surgical treatment. There was a clear and independent association between increasing age and the risk of early death, with an eightfold increase in the odds of early death in women aged 80 or more compared with those aged $<50$ at diagnosis (OR: 8.05, 95\% CI 5.96 to 10.88). In this adjusted analysis, white ethnicity was not independently associated with early death. The significant associations noted in the univariate analyses were upheld (although generally attenuated) in the multivariate model, except for chemotherapy. Women receiving chemotherapy were more likely than those not treated with chemotherapy to die within a year of their diagnosis (OR $1.49,95 \%$ CI 1.19 to 1.86 ). Surgery was associated with a reduced risk of early death (OR $0.29,95 \%$ CI 0.24 to 0.35 ), as was radiotherapy (OR $0.61,95 \%$ CI 0.51 to 0.74 ) and also tamoxifen (OR $0.64,95 \%$ CI 0.51 to 0.80 ). Women who were most recently diagnosed with breast cancer (post-2003) were less likely to die early (OR $0.71,95 \%$ CI 0.52 to 0.98 ). Women with missing data for ethnicity, presentation or metastases were at increased risk of early death compared with the reference categories.

Overall, $13.3 \%$ of women did not have surgery as part of their treatment (table 2), and this proportion was significantly greater in women who died within a year of diagnosis $(50 \%$ vs $11 \%)$. The characteristics of women who did or did not receive surgical treatment are shown in table 4 . Those receiving surgery were significantly younger, and were more likely to present via screening, to be free of metastases at diagnosis, and to have fewer comorbidities. For those of known ethnicity, there was no difference in the proportions receiving surgery between white and non-white women. However, the proportion of cases with unknown ethnicity was significantly greater in those not receiving surgery $(38.7 \%$ vs $23.8 \%)$.

In multivariate analysis (table 5), mode of presentation, older age (particularly $\geq 80$ years), distant metastases on presentation and comorbidities were independent predictors of no surgical treatment (70-79 years old vs $<50$ years old: OR $0.27,95 \%$ CI 0.23 to 0.33 ; $\geq 80$ years old versus $<50$ years old: OR 0.09 , $95 \%$ CI 0.07 to 0.10 ; symptomatic presentation versus screening: OR $0.34,95 \%$ CI 0.26 to 0.45 ; incidental presentation versus screening: OR $0.28,95 \%$ CI 0.20 to 0.40 ; distant metastases on diagnosis: OR $0.16,95 \%$ CI 0.12 to 0.20 ; severe comorbidities: OR $0.50,95 \%$ CI 0.41 to 0.62 ). White ethnicity was independently linked with an increased likelihood of surgical treatment compared with non-white ethnicity (OR $1.39,95 \%$ CI 1.16 to 1.65 ).

\section{DISCUSSION}

Poorer prognosis of older women with breast cancer has been attributed variously to treatment received, ${ }^{10-17}$ more severe disease on presentation, ${ }^{13}{ }^{18-21}$ and the presence of comorbidities. ${ }^{10}$ Stage was identified as the most important factor explaining breast cancer survival discrepancies between European countries for women

\begin{tabular}{|c|c|c|c|}
\hline \multirow{2}{*}{$\begin{array}{l}\text { Patient } \\
\text { characteristic }\end{array}$} & \multicolumn{2}{|c|}{ Surgery, number (\%) } & \multirow[b]{2}{*}{ p Value } \\
\hline & No & Yes & \\
\hline \multicolumn{4}{|c|}{ Age at diagnosis (years) } \\
\hline$<50$ & $213(10.6)$ & $3587(27.5)$ & \multirow[t]{5}{*}{$<0.001$} \\
\hline $50-59$ & $182(9.1)$ & 3557 (27.3) & \\
\hline $60-69$ & $219(10.9)$ & $2823(21.7)$ & \\
\hline $70-79$ & $526(26.3)$ & $2117(16.2)$ & \\
\hline$\geq 80$ & $862(43.1)$ & $951(7.3)$ & \\
\hline \multicolumn{4}{|l|}{ Ethnicity } \\
\hline Non-white & $238(11.9)$ & $1820(14.0)$ & \multirow[t]{3}{*}{$0.36 \dagger$} \\
\hline White & $989(49.4)$ & 8109 (62.2) & \\
\hline Not known & $775(38.7)$ & $3106(23.8)$ & \\
\hline \multicolumn{4}{|c|}{ Distant metastases at diagnosis } \\
\hline No & $680(34.0)$ & $7609(58.4)$ & \multirow[t]{3}{*}{$<0.001$} \\
\hline Yes & $151(7.5)$ & $276(2.1)$ & \\
\hline Not known & $1171(58.5)$ & $5150(39.5)$ & \\
\hline \multicolumn{4}{|c|}{ Charlson Index (comorbidities) } \\
\hline 0 & $309(15.4)$ & $6649(51.0)$ & \multirow[t]{4}{*}{$<0.001$} \\
\hline 1 & $47(2.3)$ & $360(2.8)$ & \\
\hline$\geq 2$ & $81(9.0)$ & $1434(11.0)$ & \\
\hline Not known & $1465(73.2)$ & $4592(35.2)$ & \\
\hline \multicolumn{4}{|c|}{ Diagnosis date (in relation to Cancer Plan) } \\
\hline Pre 2000 & $1336(66.7)$ & $8345(64.0)$ & \multirow[t]{3}{*}{0.025} \\
\hline $2000-2003$ & $522(26.1)$ & $3667(28.1)$ & \\
\hline Post 2003 & $144(7.2)$ & $1023(7.8)$ & \\
\hline \multicolumn{4}{|l|}{ Presentation } \\
\hline Screening & $61(3.0)$ & $2236(17.2)$ & \multirow[t]{4}{*}{$<0.001$} \\
\hline Symptoms & $1527(76.3)$ & 8767 (67.3) & \\
\hline Incidental & $117(5.8)$ & $475(3.6)$ & \\
\hline Not known & $297(14.8)$ & $1557(11.9)$ & \\
\hline \multicolumn{4}{|l|}{ Radiotherapy } \\
\hline No & $1014(50.6)$ & 2835 (21.7) & \multirow[t]{3}{*}{$<0.001$} \\
\hline Yes & 339 (16.9) & 6996 (53.7) & \\
\hline Not known & 649 (32.4) & 3204 (24.6) & \\
\hline \multicolumn{4}{|l|}{ Chemotherapy } \\
\hline No & 1107 (55.3) & 5895 (45.2) & \multirow[t]{3}{*}{$<0.001$} \\
\hline Yes & $311(15.5)$ & 4092 (31.3) & \\
\hline Not known & 584 (29.2) & 3048 (23.4) & \\
\hline \multicolumn{4}{|l|}{ Tamoxifen } \\
\hline No & $260(13.0)$ & 2233 (17.1) & \multirow[t]{4}{*}{$<0.001$} \\
\hline Yes & $1315(65.7)$ & 7916 (60.7) & \\
\hline Not known & 427 (21.3) & $2886(22.1)$ & \\
\hline Total cases & 2002 & 13035 & \\
\hline
\end{tabular}

* $p$ Value for comparison of proportions, excluding 'not known' category where present. For age, Charlson Index and Cancer Plan, test is for trend; for all other factors, test is for heterogeneity. tp Value when 'not known' category is included: $<0.001$.

given a diagnosis between 1990 and 1992, ${ }^{19}$ particularly in older age groups.

This study in more than 15000 women diagnosed as having breast cancer in the North Thames area found that age and disease severity at diagnosis were independent predictors of early death from any cause. In the women analysed here, distant metastases on diagnosis were a strong predictor of early death, increasing the odds of dying within a year of diagnosis more than eightfold (OR 8.41, 95\% CI 6.49 to 10.89). This effect 
Table 5 Crude and adjusted ORs and 95\% Cls for surgical treatment

\begin{tabular}{|c|c|c|c|c|}
\hline \multirow[b]{2}{*}{ Factor } & \multirow[b]{2}{*}{ Number of cases } & \multirow{2}{*}{$\begin{array}{l}\text { Surgical cases, } \\
\text { number (\%) }\end{array}$} & \multicolumn{2}{|l|}{ OR $(95 \% \mathrm{Cl})$} \\
\hline & & & Unadjusted & Adjusted* \\
\hline \multicolumn{5}{|c|}{ Age at diagnosis (years) } \\
\hline$<50$ & 3800 & 3587 (94.4) & $1.00(-)$ & $1.00(-)$ \\
\hline $50-59$ & 3739 & 3557 (95.1) & $1.16(0.95$ to 1.42$)$ & $0.99(0.80$ to 1.22$)$ \\
\hline $60-69$ & 3042 & 2823 (92.8) & 0.77 (0.63 to 0.93$)$ & 0.73 (0.59 to 0.89$)$ \\
\hline $70-79$ & 2643 & $2117(80.1)$ & $0.24(0.20$ to 0.28$)$ & 0.27 (0.23 to 0.33$)$ \\
\hline$\geq 80$ & 1813 & $951(52.5)$ & 0.07 (0.06 to 0.08$)$ & $0.09(0.07$ to 0.10$)$ \\
\hline \multicolumn{5}{|l|}{ Ethnicity } \\
\hline Non-white & 2058 & $1820(88.4)$ & $1.00(-)$ & $1.00(-)$ \\
\hline White & 9098 & 8109 (89.1) & $1.07(0.92$ to 1.25$)$ & 1.39 (1.16 to 1.65$)$ \\
\hline Not known & 3881 & $3106(80.0)$ & $0.52(0.45$ to 0.61$)$ & $0.93(0.77$ to 1.11$)$ \\
\hline \multicolumn{5}{|c|}{ Distant metastases at diagnosis } \\
\hline No & 8289 & 7609 (91.8) & $1.00(-)$ & $1.00(-)$ \\
\hline Yes & 427 & $276(64.6)$ & $0.16(0.13$ to 0.20$)$ & $0.16(0.12$ to 0.20$)$ \\
\hline Not known & 6321 & $5150(81.5)$ & 0.39 (0.36 to 0.43$)$ & 0.36 (0.31 to 0.40$)$ \\
\hline \multicolumn{5}{|c|}{ Charlson Index (comorbidities) } \\
\hline 0 (minor) & 6958 & $6649(95.6)$ & $1.00(-)$ & $1.00(-)$ \\
\hline 1 (moderate) & 407 & $360(88.5)$ & $0.36(0.26$ to 0.49$)$ & 0.70 (0.49 to 0.99$)$ \\
\hline $2+($ severe $)$ & 1615 & $1434(88.8)$ & $0.37(0.30$ to 0.45$)$ & 0.50 (0.41 to 0.62$)$ \\
\hline Not known & 6057 & $4592(75.8)$ & $0.15(0.13$ to 0.17$)$ & $0.20(0.17$ to 0.23$)$ \\
\hline \multicolumn{5}{|c|}{ Diagnosis date (in relation to Cancer Plan) } \\
\hline Pre 2000 & 9681 & $8345(86.2)$ & $1.00(-)$ & $1.00(-)$ \\
\hline $2000-2003$ & 4189 & 3667 (87.5) & $1.12(1.01$ to 1.25$)$ & $1.11(0.97$ to 1.27$)$ \\
\hline Post 2003 & 1167 & $1023(87.7)$ & $1.14(0.95$ to 1.37$)$ & 0.75 (0.60 to 0.94$)$ \\
\hline \multicolumn{5}{|l|}{ Presentation } \\
\hline Screening & 2297 & 2236 (97.3) & $1.00(-)$ & $1.00(-)$ \\
\hline Symptoms & 10294 & 8767 (85.2) & $0.16(0.12$ to 0.20$)$ & $0.34(0.26$ to 0.45$)$ \\
\hline Incidental & 592 & 475 (80.2) & $0.11(0.08$ to 0.15$)$ & $0.28(0.20$ to 0.40$)$ \\
\hline Not known & 1854 & 1557 (84.0) & $0.14(0.11$ to 0.19$)$ & 0.39 (0.29 to 0.53$)$ \\
\hline
\end{tabular}

was independent of age and treatment. It was also independent of patient comorbidities, although this should be interpreted with some caution, as comorbidity data were available only for the $60 \%$ of participants who could be successfully linked to the HES dataset. Surgery was strongly associated with a reduced risk of early death, and older patients were less likely to receive surgery.

Great improvements in cancer services have been made during the past decade. To investigate whether the implementation of the Cancer Plan has had any observable effect on survival, this research included a categorical variable controlling for calendar period of diagnosis in the multivariate analyses. This method was similar to that used by Rachet et al in their assessment of the NHS Cancer Plan for England. In our study, women given a diagnosis after 2003 had reduced odds of early death compared with women given a diagnosis before the Cancer Plan was published (OR 0.71, 95\% CI 0.52 to 0.98). This suggests a survival benefit resulting from changes to cancer services after 2000.

While women of white ethnicity were at greater odds of early death in univariate analyses, this association was no longer significant when the model was adjusted for the other covariates. The white women were in general older than the non-white women, and this may explain these findings. However, in the adjusted analysis, white women were more likely to be treated surgically than those belonging to non-white ethnic groups. These results should perhaps be treated with caution, given the large proportion $(26 \%)$ of cases for which ethnicity was not known.

Radiotherapy and tamoxifen treatments were independently associated with reduced likelihood of early death, while chemotherapy was associated with increased odds of dying within a year of diagnosis (OR 1.49, 95\% 1.19 to 1.86$)$. This relationship with chemotherapy is likely to be a reflection of selection bias, whereby only the most severe cases are given this form of treatment. A similar bias, but in the opposite direction, may apply to surgery-that is, with very ill patients selectively not being operated upon. However, the association between surgery and death within 1 year remained apparent in a model correcting for age and comorbidity. These findings are consistent with those in a recent study by Brewster $e t a l^{22}$ that found age, deprivation, emergency admission, tumour stage, and grade and absence of treatment were independent factors associated with death within 30 days of diagnosis.

A recent report from the National Cancer Intelligence Network based on data from 2007 confirms that a high proportion of older women in the UK do not receive surgical treatment: $61 \%$ of women aged over $80 \mathrm{did}$ not 
have surgery. ${ }^{23}$ This group is likely to have a particularly poor prognosis. Nearly $40 \%$ of women who died early in our study were aged 80 years or over, and $66 \%(252 / 383)$ of them had not had surgery.

In our study, age was strongly inversely associated with the likelihood of receiving surgery. This reflects the welldescribed pattern in other studies of older women being less likely to receive treatment than younger women. ${ }^{10} 24$ Women over 80 years old attending breast units in Manchester in 2002, for example, were less likely to have surgery than women aged 65-79 years even after adjustment for poorer general health, including comorbidities. ${ }^{11}$

Patient comorbidity has been shown to be a potentially important confounder in studies of treatment received, ${ }^{15}{ }^{25}$ but our analyses suggest that older women are less likely to receive surgery even after adjustment for comorbidities. Comorbidity data were missing for approximately $40 \%$ of participants. Patients with missing comorbidity data were less likely to receive surgery, although there was no association between these missing data and early death after adjustment for other factors.

One potential limitation of this study is missing information. Women with missing data on ethnicity, presentation and distant metastases were more likely to die within a year of their diagnosis and were less likely to receive surgical treatment. They may represent women who were seriously ill at diagnosis and who were not scheduled for surgery. An analysis of the characteristics of patients with several missing data elements suggests that these women tend to be older, have more severe disease (as determined by a proxy of tumour size), and are more likely to die early. In addition, a failure to record important details relating to their diagnosis and treatment may be an indication that such patients are receiving worse care. With respect to this study, if women with missing information have worse disease and are generally older, then the estimates of association between these variables and early death will be biased towards underestimates of the true effects.

Retrospective analyses rely on records in which some information may be inaccurate. In this study a particular effort was made to ensure that the surgical status of women was recorded correctly, as this was considered an important marker of the quality of treatment and was expected to be strongly associated with outcome. Time and resource constraints precluded this additional effort being extended to other variables to verify database entries. However, an earlier study looking at trends in the treatment of breast cancer ${ }^{26}$ concluded that the audit database was a reasonably reliable source of such data.

The effects of deprivation on disease severity and ultimately on mortality were not explored in this study. Such analyses rely on potential patient identifiers, such as postcode data, that were not available to us. Deprivation has been linked to poorer patient outcomes for UK patients with breast cancer in several studies, ${ }^{22} 27-29$ and stated aims of the Cancer Plan and the Cancer Reform

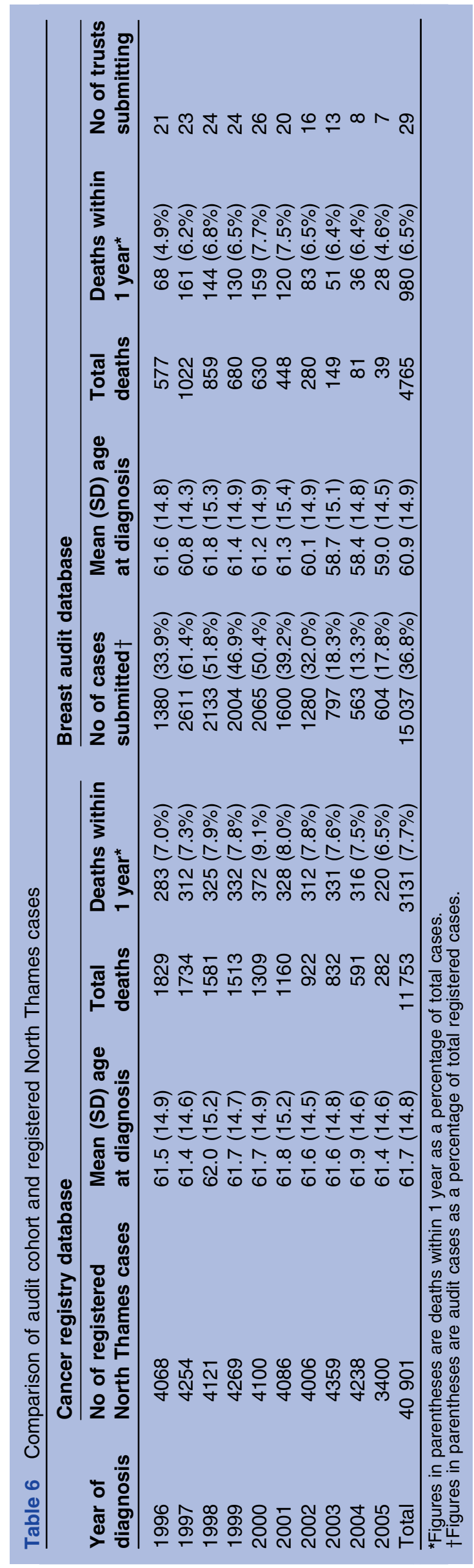


Strategy ${ }^{30-32}$ are to tackle the inequalities in cancer survival between different socioeconomic groups in England.

We suspect a complex relationship between the exposures studied here, some of which may be on the same causal pathway for early death. For example, high age and comorbidity may be rational and adequate reasons for not offering surgery. While a number of patient and treatment characteristics were strongly and independently linked with early death, these associations must be interpreted with caution and with a consideration for unmeasured confounding factors. For instance, the selection of a patient's treatment will depend on a number of factors, including some not measured here, such as their own preferences or established practices within the organisation in which they are treated. ${ }^{33}$ Furthermore, their presentation to health services depends, among other factors, on access to those services and knowledge of cancer symptoms. Many of these variables may be linked to both risk factors and outcomes and they have not been assessed in this study. However, for any underlying confounder to explain the strong statistical associations seen in our data, they would need to have a very strong correlation with death within a year of diagnosis.

Five-year relative survival in our sample (based on life tables for London during the period 1996-2001) was $84.1 \%$. This is similar to recent estimates from the Office for National Statistics, ${ }^{34}$ which reports a value of $82 \%$ for women given a diagnosis between 2000 and 2006. Thus our cohort sample is likely to be reasonably representative of the UK population of women diagnosed as having breast cancer during this period. Table 6 compares the audit data with the total registrations for female breast cancer in the North Thames region at TCR. Mean age at diagnosis was similar throughout the study period. Likewise, the proportion of patients dying within 1 year of diagnosis was broadly similar, although slightly lower in the audit database $(6.5 \%$ vs $7.7 \%$ overall.) The proportion of total cases represented in the audit varied between $61 \%$ in 1997 and $13 \%$ in 2004, with an overall figure of $37 \%$. (The decrease in the number of registered cases in 2005 is an artefact due to changes in the TCR catchment area.) In general, there was a higher representation in the earlier years, which may have implications for the applicability of the results to more recent times.

\section{CONCLUSIONS}

Our findings offer detailed insights into the determinants of death in the first year after a diagnosis of breast cancer, a period shown to be important in international comparisons. As expected, early death is linked to older age and to the presence of comorbidities. Comorbidities can be addressed in the long run through general health policy, but two other determinants of early death identified by this study are potential avenues for intervention.

First, the findings relating to disease severity lend empirical support to the notion that late diagnosis is a major determinant of early death. This supports the rationale for projects that focus on increasing awareness of breast symptoms and the importance of screening. Second, surgery is independently associated with a large reduction in the risk of early death, and older women were-independently of disease severity and comorbidity-much less likely to receive surgery. Assuming surgery is an indicator of attempts at curative treatment, there may be benefits of increased treatment activity for older women.

Acknowledgements Ceilidh Stapelkamp undertook this work in a personal capacity while completing her Master's degree at King's College London Medical School, Department of Public Health and Division of Cancer Studies.

Funding This research received no specific grant from any funding agency in the public, commercial or not-for-profit sectors.

\section{Competing interests None.}

Contributors DR, LH and CS designed the study. DR, DT and CS collated and analysed the data. CS wrote the first draft, and DR, HM and LH finalised the manuscript. All authors contributed to the interpretation of the data, and reviewed and revised the manuscript, and have read and approved the final draft. All authors had full access to all of the data (including statistical reports and tables) in the study and can take responsibility for the integrity of the data and the accuracy of the data analysis.

Provenance and peer review Not commissioned; externally peer reviewed.

Data sharing statement No additional data available.

\section{REFERENCES}

1. Berrino F, Verdecchia A, Lutz JM, et al. Comparative cancer survival information in Europe. Eur J Cancer 2009;45:901-8.

2. Verdecchia A, Francisci S, Brenner $\mathrm{H}$, et al. Recent cancer survival in Europe: a 2000-02 period analysis of EUROCARE-4 data. Lancet Oncol 2007;8:784-96.

3. Sant M, Capocaccia R, Verdecchia A, et al. Survival of women with breast cancer in Europe: variation with age, year of diagnosis and country. The EUROCARE Working Group. Int J Cancer 1998:77:679-83.

4. Møller H, Sandin F, Bray F, et al. Breast cancer survival in England, Norway and Sweden: a population-based comparison. Int $J$ Cancer 2010;127:2630-8

5. Beral V, Peto R. UK cancer survival statistics. BMJ 2010;341:c4112.

6. Møller $\mathrm{H}$, Richards $\mathrm{S}$, Hanchett $\mathrm{N}$, et al. Completeness of case ascertainment and survival time error in English cancer registries: impact on one-year survival estimates. Br J Cancer 2011;105:170-6.

7. Robinson D, Sankila R, Hakulinen T, et al. Interpreting international comparisons of cancer survival: the effects of incomplete registration and the presence of death certificate only cases on survival estimates. Eur J Cancer 2007;43:909-13.

8. Rachet $\mathrm{B}$, Maringe $\mathrm{C}$, Nur $\mathrm{U}$, et al. Population-based cancer survival trends in England and Wales up to 2007: an assessment of the NHS cancer plan for England. Lancet Oncol 2009;10:351-69.

9. Charlson ME, Pompei P, Ales KL, et al. A new method of classifying prognostic comorbidity in longitudinal studies: development and validation. J Chronic Dis 1987;40:373-83.

10. Janssen-Heijnen ML, Maas HA, Houterman S, et al. Comorbidity in older surgical cancer patients: influence on patient care and outcome. Eur J Cancer 2007;43:2179-93.

11. Lavelle K, Moran A, Howell A, et al. Older women with operable breas cancer are less likely to have surgery. Br J Surg 2007;94:1209-15.

12. Haggstrom DA, Quale C, Smith-Bindman R. Differences in the quality of breast cancer care among vulnerable populations. Cancer 2005; 104:2347-58.

13. Ugnat AM, Xie L, Morriss J, et al. Survival of women with breast cancer in Ottawa, Canada: variation with age, stage, histology, grade and treatment. Br J Cancer 2004;90:1138-43.

14. Bouchardy C, Rapiti E, Fioretta G, et al. Undertreatment strongly decreases prognosis of breast cancer in elderly women. J Clin Oncol 2003;21:3580-7.

15. Yancik R, Wesley MN, Ries LA, et al. Effect of age and comorbidity in postmenopausal breast cancer patients aged 55 years and older. JAMA 2001;285:885-92. 
16. Busch E, Kemeny M, Fremgen A, et al. Patterns of breast cancer care in the elderly. Cancer 1996;78:101-11.

17. Ballard-Barbash R, Potosky AL, Harlan LC, et al. Factors associated with surgical and radiation therapy for early stage breast cancer in older women. J Natl Cancer Inst 1996;88:716-26.

18. Eaker S, Dickman PW, Bergkvist L, et al. Differences in management of older women influence breast cancer survival: results from a population-based database in Sweden. PLoS Med 2006;3:e25.

19. Sant M, Allemani C, Capocaccia R, et al. Stage at diagnosis is a key explanation of differences in breast cancer survival across Europe. Int $J$ Cancer 2003;106:416-22.

20. Soerjomataram I, Louwman MW, Ribot JG, et al. An overview of prognostic factors for long-term survivors of breast cancer. Breast Cancer Res Treat 2008;107:309-30.

21. Carter CL, Allen C, Henson DE. Relation of tumor size, lymph node status, and survival in 24,740 breast cancer cases. Cancer 1989;63:181-7

22. Brewster DH, Clark DI, Stockton DL, et al. Characteristics of patients dying within 30 days of diagnosis of breast or colorectal cancer in Scotland, 2003-2007. Br J Cancer 2011;104:60-7.

23. National Cancer Intelligence Network. The Second All Breast Cancer Report. NCIN, 2011. http://www.ncin.org.uk/home.aspx (accessed 19 Jun 2011).

24. Lavelle K, Todd C, Moran A, et al. Non-standard management of breast cancer increases with age in the UK: a population based cohort of women 65 years. Br J Cancer 2007;96:1197-203.
25. Cronin-Fenton DP, Norgaard M, Jacobsen J, et al. Comorbidity and survival of Danish breast cancer patients from 1995 to 2005. Br J Cancer 2007;96:1462-8.

26. Tataru D, Robinson D, Moller $\mathrm{H}$, et al. Trends in the treatment of breast cancer in Southeast England following the introduction of national guidelines. J Public Health (Oxf) 2006;28:215-17.

27. Macleod U, Ross S, Gillis C, et al. Socio-economic deprivation and stage of disease at presentation in women with breast cancer. Ann Oncol 2000;11:105-7.

28. Macleod U, Ross S, Twelves C, et al. Primary and secondary care management of women with early breast cancer from affluent and deprived areas: retrospective review of hospital and general practice records. BMJ 2000;320:1442-5.

29. Downing A, Prakash K, Gilthorpe MS, et al. Socioeconomic background in relation to stage at diagnosis, treatment and survival in women with breast cancer. Br J Cancer 2007;96:836-40.

30. Department of Health. The NHS Cancer Plan: A Plan for Investment a Plan for Reform. London: Department of Health, 2000.

31. House of Commons. The NHS Cancer Plan: A Progress Report London: The Stationery Office, 2005.

32. Department of Health. Cancer Reform Strategy. London: Department of Health, 2007.

33. Hoy AR, Patrick $\mathrm{H}$, Campbell $\mathrm{B}$, et al. Measuring the influence of colleagues on a consultant team's use of breast conserving surgery Int J Technol Assess Health Care 2010;26:156-62.

34. Office for National Statistics. Breast Cancer: Incidence Rates Rise, Mortality Rates Fall. 2010. http://www.statistics.gov.uk/cci/nugget. asp?id=575 (accessed 19 Jun 2011). 